\title{
GERENCIAMENTOS DE RESÍDUOS QUÍMICOS EM INSTITUIÇÕES DE ENSINO E PESQUISA
}

Os Institutos e Departamentos de Química das Universidades, além de todas as unidades que utilizam produtos químicos em suas rotinas de trabalho, têm sido confrontados, ao longo de muitos anos, com o problema relacionado ao tratamento e à disposição final dos resíduos gerados em seus laboratórios de ensino e pesquisa.

Esses resíduos diferenciam-se daqueles gerados em unidades industriais por apresentarem baixo volume, mas grande diversidade de composições, o que dificulta a tarefa de estabelecer um tratamento químico e/ou uma disposição final padrão para todos.

De maneira geral, esse problema atinge graves proporções e tem sido relegado a um plano secundário. Na maioria dos casos os resíduos são estocados de forma inadequada e ficam aguardando um destino final, isso quando são estocados. Infelizmente, a cultura ainda dominante é de descartá-los na pia do laboratório, já que a maioria das instituições públicas brasileiras de ensino e pesquisa não tem uma política institucional clara que permita um tratamento global do problema.

A Química é uma das ciências básicas que mais benefícios trouxe à humanidade ao longo dos últimos tempos. Com os seus vários segmentos, ela permeia a vida de todas as pessoas que vivem em uma sociedade moderna e de alto grau tecnológico (p. ex., fármacos, materiais especiais, defensivos agrícolas, insumos para vários segmentos industriais, materiais de limpeza, higiene pessoal, beleza, etc.). Infelizmente, esse quadro, como uma moeda, não tem um lado só. O mau uso dessa Ciência tem causado graves problemas à humanidade e vem sendo responsável pela percepção negativa da Química.

Dentro desse quadro, pode-se dizer que um dos problemas mais graves relacionado ao mau uso da Química refere-se aos danos ambientais. Para contornar essa situação, as legislações ambientais de todos os países do mundo, inclusive a do Brasil, vêm evoluindo e se adaptando às novas realidades, visando coibir severamente os abusos. Essas legislações vêm também incorporando novas exigências no monitoramento das emissões de voláteis no ar e no lançamento de resíduos industriais nos corpos aqüíferos.

As Universidades brasileiras, que realizam pesquisas nas áreas da Química e de ciências afins, não podem ficar alheias às drásticas mudanças estruturais que vêm ocorrendo na legislação ambiental do nosso país.

Devemos estar conscientes de que os benefícios oriundos da nossa atividade científica e profissional (publicações, patentes, reconhecimento científico, desenvolvimento de novos produtos e tecnologias) podem gerar, paralelamente, resíduos químicos de diversos graus de periculosidade, que podem necessitar de tratamento químico adequado, antes de serem enviados à disposição final ${ }^{1}$

Apesar de diversas ações isoladas ${ }^{2-6}$, essa questão precisa ser encarada coletivamente por toda a comunidade científica $e$ pelos órgãos de fomento, dada sua relevância. O primeiro passo para enfrentar este desafio é assumir conscientemente a nossa responsabilidade para com os rejeitos gerados em nossos laboratórios e, depois, lutar pelo estabelecimento de uma política institucional de gerenciamento desses resíduos.

A nossa responsabilidade tem também um outro aspecto que precisa ser considerado. Como formadores de mão-de-obra especializada, precisamos despertar a atenção dos nossos alunos de graduação e pós-graduação para essa questão e lhes fornecer as ferramentas básicas, que lhes permitam exercer suas atividades profissionais de forma "limpa". Não devemos esquecer que, além de formar químicos, estamos contribuindo para a formação de cidadãos compromissados com a nação.

Nos últimos anos ações isoladas vêm sendo desenvolvidas por várias Instituições de Ensino Superior (notadamente públicas) e pela SBQ, visando aumentar a visibilidade dos problemas referentes ao gerenciamento de resíduos químicos. Neste aspecto, a Química Nova tem tido uma participação importante na divulgações de novas experiências no gerenciamento de resíduos ${ }^{7}$. De igual importância são os eventos científicos nacionais (ex. ENSEQUI, SBQ-Sul) e internacionais (International Symposium on Residue Management in Universities, Santa Maria, RS), os quais contribuem para a formação de uma nova postura crítica sobre o problema.

Apesar do exposto, no Brasil já vêm ocorrendo há alguns anos encontros para se discutir, entre outros temas, a gestão de resíduos perigosos; um exemplo disso são os Encontros Nacionais de Segurança em Química ENSEQUI. O primeiro deles ocorreu em 2000 na UNICAMP em Campinas - SP e o enfoque principal foi a discussão de estratégias para implementação de uma política de segurança em laboratórios e o tratamento dos resíduos químicos nas universidades. No $2^{\circ}$ ENSEQUI, realizado em 2002 na UFRGS em Porto Alegre - RS, buscou-se a interação entre indústrias, universidades e o poder público, dentro de suas realidades na área de segurança e gestão de resíduos. O $3^{\circ}$ ENSEQUI, realizado em 2004 na UFF em Niterói - RJ, contou com a presença de 142 participantes. Foram ministrados quatro mini-cursos, proferidas três palestras e duas mesas-redondas e uma sessão de painéis com 33 trabalhos apresentados. Foram convidados professores das instituições UNICAMP, UFRGS, UFF, UFRJ, PUC-RJ, UCB, UFPR, CEFETEQ-RJ, Merck, CENPES/Petrobrás, Bayer, FEEMA, dentre outras. O foco do evento foi a participação da administração central das Instituições de Ensino Superior (IFE's) e a implementação de políticas de segurança e gestão ambiental, especialmente de resíduos perigosos. $\mathrm{Na}$ oportunidade foi discutido e elaborado um documento intitulado "CARTA DE NITERÓI", a ser enviado a diversos ministérios e órgãos de fomento após a aprovação nas IFE's signatárias, propondo ações que visam a implementação de programas na área de gerenciamento de resíduos perigosos e, em âmbito mais geral, da gestão ambiental, cujo texto final segue abaixo:

\section{CARTA DE NITERÓI}

O cenário ambiental tem servido como painel de fundo para as discussões que visam minimizar os riscos e criar condições para o desenvolvimento de processos de gestão sustentáveis dos Campi Universitários. Vários eventos, de âmbito nacional e internacional, têm abordado de forma consistente a temática, e dentro deste contexto inserem-se os Encontros Nacionais de Segurança em Química (ENSEQUI).

Por ocasião do $3^{\circ}$ ENSEQUI, realizado na Universidade Federal Fluminense (UFF), em Niterói, RJ, foram discutidos os aspectos mais relevantes relacionados ao gerenciamento de resíduos químicos e ao atendimento das exigências da legislação ambiental e de segurança vigentes.

Nesta terceira edição do evento foi organizada uma reunião em que foram convidados os Pró-Reitores das Instituições de Ensino e Pesquisa de todo o país. Esta reunião teve como objetivo propor ações que visassem disseminar a cultura e a prática do gerenciamento dos resíduos perigosos principalmente oriundos das atividades de ensino e pesquisa. As Instituições presentes e signatárias deste documento reconhecem a importância e relevância do tema, mas enfrentam problemas de ordem orçamentária para a implementação de programas na área de gerenciamento de resíduos perigosos e, em âmbito mais geral, da gestão ambiental.

Assim, para transpor dificuldades orçamentárias, de modo que as Instituições de Ensino possam colocar em prática ações que minimizem o impacto ambiental e o risco aos envolvidos nas suas atividades de ensino e pesquisa e, para que sejam formados profissionais com a consciência da necessidade de atenção a resíduos que tragam riscos a indivíduos ou ao ambiente, sugere-se as seguintes ações aos órgãos de financiamento e regulamentação do ensino e pesquisa no país:

- que sejam alocados fundos e lancados editais específicos para Gestão Ambiental e Gerenciamento de Resíduos Perigosos nas Instituições de Ensino e Pesquisa. Entendem-se como resíduos perigosos, os resíduos químicos, biológicos e radioativos gerados nas atividades de ensino e pesquisa;

- que se crie um grupo de trabalho de especialistas para propor Normas de Segurança em Química para as Instituições de Ensino e Pesquisa;

- que se crie um grupo de trabalho de especialistas para estruturar o gerenciamento dos resíduos perigosos visando o futuro Licenciamento Ambiental nas Instituições de Ensino e Pesquisa e

- que se inclua como critério de qualidade para fins de avaliação por parte do MEC e da CAPES, a existência, ou projeto em implantação, de programa de gestão de resíduos perigosos em cursos de graduação e pós-graduação das Instituições de ensino e pesquisa.

Annelise E. Gerbase - IQ/UFRGS Fernando S. Coelho - IQ/UNICAMP Patrícia F. L. Machado - IQ/UFF Vitor F. Ferreira - Editor de QN

\section{REFERÊNCIAS}

1. Afonso, J. C.; Noronha, L. A.; Felipe, R. P.; Freidinger, N.; Quim. Nova 2003, 26, 602

2. Demaman, A. S.; Funk, S.; Hepp, L. U.; Adário, A. M. S.; Pergher, S. B. C.; Quim. Nova 2004, 27, 674.

3. Alberguini, L. B. A.; Silva, L. C.; Rezende, M. O. O.; Quim. Nova 2003, 26, 291.

4. Amaral, S. T.; Machado, P. F. L.; Peralba, M. C. R.; Câmara, M. R.; Santos, T.; Berleze, A. L.; Falcão, H. L.; Martinelli, M.; Gonçalves, R. S.; Oliveira, E. R.; Brasil, J. L.Araujo, M. A.; Borges, A. C. A.; Quim. Nova 2001, 24, 419

5. Cunha, C. J.; Quim. Nova 2001, 24, 424.

6. Afonso, J. C.; Silveira, J. A.; Oliveira, A. S.; Lima, R. M. G.; Quim. Nova 2005, 28, 157

7. Jardim, W. F.; Quim. Nova 1998, 21, 671 . 